7 Chen W, Liu TJ, Yang YC, Happle R: Angioma serpiginosum arranged in a systematized segmental pattern suggesting mosaicism. Dermatology 2006; 213: 236-238.

8 Grzeschik KH, Bornholdt D, Oeffner F et al: Deficiency of PORCN, a regulator of Wnt signaling, is associated with focal dermal hypoplasia. Nat Genet 2007; 3: 833-835.

9 Zala L, Ettlin C, Krebs A: Fokale dermale Hypoplasie mit Keratokonus, Ösophaguspapillomen und Hidrokystomen. Dermatologica 1975; 150: 176-185.

10 Brinson RR, Schuman BM, Mills LR, Thigpen S, Freedman S: Multiple squamous papillomas of the esophagus associated with Goltz syndrome. Am J Gastroenterol 1987; 82: 1177-1179.

11 Gordjani N, Herdeg S, Ross UH, Grimme H, Kleinschmidt M, Brandis M: Focal dermal hypoplasia (Goltz-Gorlin syndrome) associated with obstructive papillomatosis of the larynx and hypopharynx. Eur J Dermatol 1999; 9: 618-620.

\section{Reply to Happle}

European Journal of Human Genetics (2009) 17, 882; doi:10.1038/ejhg.2009.49; published online 1 April 2009

We are honoured by the attention given by Professor Happle to our recent papers on angioma serpiginosum (AS) and PORCN mutations. ${ }^{1,2}$ Surely the issue here is whether the clinical diagnosis AS is right, or whether the phenotype in the family we described should be regarded as a mild form of focal dermal hypoplasia $(\mathrm{FDH}$, also known as Goltz-Gorlin syndrome). We published detailed clinical data in the first paper in 2007. Contrary to Professor Happle, we have not observed focal hypoplasia of the skin by personal investigations of any of the probands. Two skin biopsies of affected areas have been taken and carefully examined by experienced pathologists. Again no dermal hypoplasia was observed. Also contrary to the statement by Professor Happle, none of the patient had bald patches involving the scalp, only sparse and thin hair occurred. Indeed these signs were so mild that they remained unnoticed until the idea arose in one of us (RCMH) that AS and FDH could be allelic entities. The chance discovery of concomitant non-symptomatic esophageal papillomatosis was a major additional clue for this. There were many features common in FDH that were missing in the family, patients did not have ophthalmological signs or symptoms, they had no papillomas around orifices, no clefting, not the thin and anteverted pinnae that are very frequent in $\mathrm{FDH}$, no prominent coccyx, and missed even any limb anomaly. However, we agree with Professor Happle that a patient may still have FDH without these additional features. This made us state that the patients have AS and only resemble FDH, and that the two entities are allelic.

Professor Happle mentions in his letter that there is 'not the slightest indication' that AS is an X-linked condition.
However, it is known that the vast majority of cases with AS are females. ${ }^{3}$ Furthermore, in several patients affected skin following Blaschko lines has been described, ${ }^{4}$ and no male to male transmission has been reported. Indeed, OMIM mentions that the few male cases with AS that have been described 'may actually represent somatic mosaicism of an X-linked gene'. There are very rare families reported in which AS seems to segregate in an autosomal dominant manner, although in one of these families X-linked inheritance can be excluded. It may be that AS is a genetically heterogeneous condition. Professor Happle suggests that AS can be explained as a somatic mosaicism for an autosomal dominant acting gene. We agree that sporadic AS may well be explained by somatic mosaicism, but the gene involved can be both X-linked and autosomal dominant. Biopsies of affected areas in a large series of patients with AS may be needed to investigate this in more detail.

We conclude that there is overwhelming evidence that AS is an X-linked disorder, and that the features in the family we described would be well in agreement with the diagnosis of AS and only resemble FDH as not only FDH itself is absent, but all the other common features of FDH are also missing. Owing to this we favour studying the rare familial AS occurrence for PORCN mutations.

Gunnar Houge $e^{*, 1}$ and Raoul CM Hennekam ${ }^{2,3}$ ${ }^{1}$ Center for Medical Genetics and Molecular Medicine, Haukeland University Hospital, Bergen, Norway;

${ }^{2}$ Clinical and Molecular Genetic Unit, Institute of Child Health, UCL, London, UK;

${ }^{3}$ Department of Pediatrics, Academic Medical Center, University of Amsterdam, Amsterdam, The Netherlands

${ }^{*}$ Correspondence: Professor G Houge, Center for Medical Genetics and Molecular Medicine, Haukeland University Hospital, Jonas Liesvei, Haukeland Universitetssykehus, Bergen 5021, Norway. Tel: +475597 5444; Fax: + 475597 5479; E-mail: gunnar.houge@helse-bergen.no

\section{References}

1 Blinkenberg EO, Brendehaug A, Sandvik AK, Vatne O, Hennekam RC, Houge G: Angioma serpiginosum with oesophageal papillomatosis is an X-linked dominant condition that maps to Xp11.3-Xq12. Eur J Hum Genet 2007; 15: 543-547.

2 Houge G, Oeffner F, Grzeschik KH: An Xp11.23 deletion containing PORCN may also cause angioma serpiginosum, a cosmetic skin disease associated with extreme skewing of X-inactivation. Eur J Hum Genet 2008; 16: 1027-1028.

3 Frain-Bell W: Angioma serpiginosum. Br J Dermatol 1957; 69: $251-268$.

4 Gerbig AW, Zala L, Hunziker T: [Angioma serpiginosum, a skin change along Blaschko lines?]. Hautarzt 1995; 46: 847-849. 